\title{
Improving geotechnical properties of clayey soil using polymer material
}

\author{
Hussein Karim ${ }^{1, *}$ and Kawther Al-Soudany ${ }^{1}$ \\ ${ }^{\mathbf{1}}$ Building and Construction Engineering Department, University of Technology, Baghdad, Iraq
}

\begin{abstract}
This study illustrates the application of polymer material for clayey soil stabilization. The article will focus on studying the strength behavior of the clayey soils reinforced with homogenously polymer fiber. In the current research, "polypropylene" was selected as polymer material to reinforce the natural clay soil. This polymer fiber was added to the clayey soil with four different percentages of $(0,1.5,3$, and $5 \%)$ by weight of soil. Various tests with different polymer contents were performed to study the effect of using such a polymer as a stabilizing agent on geotechnical properties of clay. As the fiber content increases, the optimum moisture content (OMC) is increased while the specific gravity decreases. For Atterberg's limits, the results indicated increasing liquid limit and plasticity index while decreasing plastic limit with increase in polymer content. The outcomes of the tests also reflected a considerable improvement in the unconfined compressive strength with noticeable improvement in the shear strength parameter (undrained shear strength, $\mathrm{c}_{\mathrm{u}}$ ) of the treated soils. The undrained shear strength obtained from treated soil with $5 \%$ polymer addition is more than three times that of the untreated soil. With an increase in polymer content, the consolidation parameters (Compression index $C_{c}$ and recompression index $C_{r}$ ) decreases. Finally, the benefit of the reinforcement is increased with increasing polymer fiber content.
\end{abstract}

\section{Introduction}

For all engineering structures constructed on weak clayey soils, deformations occur when these soils are exposed to any additional load or due to dissolution of clay when these soils get wet, soaked or leached with water. These deformations may cause a significant failure (cracking, tilting and collapse) of the foundation or earth structures. Many problems regarding foundation such as collapse in road construction projects are associated with the consolidation of the clayey soil layers. Thus, many researchers employ soil stabilization techniques for ground improvement to achieve the required performance $[1,2]$.

Soil stabilization refers to the addition of a cementing material (s) to the soil to improve one or more of its geotechnical properties. The addition of stabilizing agents to natural soils has a long history either by mechanical mixing to obtain a homogeneous mixture or by adding the stabilizing material to fill the soil voids [3-5].

Several materials (natural, fabricated and byproduct materials) have been used as stabilizers for adaptation of clayey soils. The application of various inorganic or organic additives such as lime, Portland cement, asphalt binder, fly ash, rice husk ash etc., or their combinations often create the modification of soil properties including cementation of soil particles [6, 7].

Clay soils are mostly found in Iraq (more than 20\%) particularly in its middle and southern parts and around $35 \%$ of the former portions are weak. Thus, the problems of this soil have been taken in consideration by many Iraqi geologists and civil engineers since it is often used as natural foundation bases for structures. There are most complex engineering problems in the clay soil, especially when accompanied by environmental changes in moisture content and undergoes large settlement under long term of loads. Failure of different structures constructed on clay soils in various locations in Iraq were recorded such as Ammara, Nasiriya and Basra that are characterized by their low undrained shear strength $(<40 \mathrm{kPa})$ and compression index as high as 0.3 were reported $[2,8]$. Thus, it is necessary to improve large areas covered by weak clay soil that has created problems to roads and airports built on clay soils because of their low bearing capacity.

This research concentrates on investigating experimentally the feasibility of stabilizing and improving the geotechnical properties of soft clay soil using a polymer fiber material in different proportions and to study the polymer effect on the engineering characteristics of the stabilized clay.

\section{Materials used and methodology}

\subsection{Materials used}

\subsubsection{Soil used}

The soil used for this study was taken from Alsadda site in Baghdad. At the beginning, the soil natural moisture content was determined immediately. After that, the soil samples were spread out in the laboratory for two weeks

Corresponding author: husn_irq@yahoo.com 
for air-drying at room temperature to remove the natural water which may influence the analysis. The soil is of low plasticity (CL) classified according to Unified Soil Classification System (USCS). The grain size distribution and engineering properties of the used soil are presented in Figure 1 and Table 1, respectively.

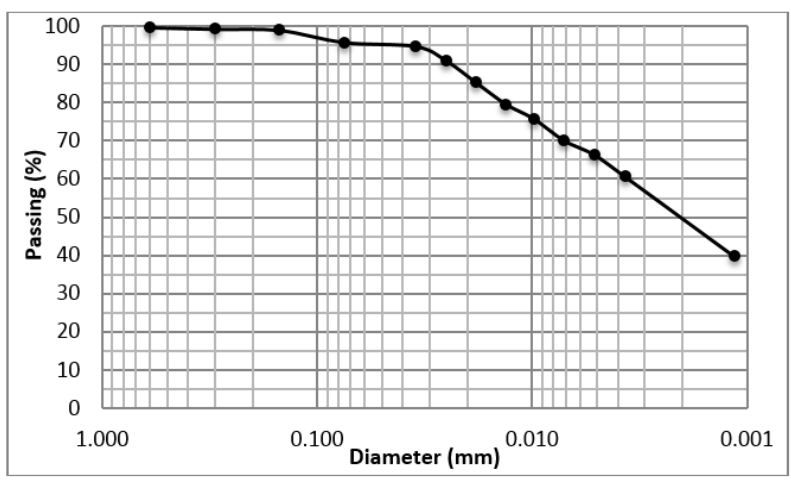

Fig. 1. Grain size distribution curve.

Table 1. Engineering properties of the used soil.

\begin{tabular}{|l|c|c|}
\hline \multicolumn{1}{|c|}{ Property } & Value & Standard \\
\hline Liquid limit (L.L. \%) & 47 & ASTM D 4318-00 [9] \\
\hline Plastic limit (P.L. \%) & 23 & ASTM D 4318-00 [9] \\
\hline Plasticity index (P.I. \%) & 24 & ASTM D 4318-00 [9] \\
\hline Specific gravity & 2.69 & ASTM D 854-02 [10] \\
\hline Gravel \% & 0 & ASTM D 422-63 [11] \\
\hline Sand \% & 4.2 & ASTM D 422-63 [11] \\
\hline Silt \% & 29.8 & ASTM D 422-63 [11] \\
\hline Clay \% & 66 & ASTM D 422-63 [11] \\
\hline Activity & 0.41 & ASTM D 422-63 [11] \\
\hline
\end{tabular}

\subsubsection{Polymer used}

A commercial product of polypropylene (PP), also known as polypropene, is a thermoplastic polymer utilized in many implementations including textiles and packaging. With the addition of such polymer, the material become tough and abnormally rigid and chemically resistant. Scientifically, polypropylenes are polymers consisting of repeated branched units derived from propane and having the formula $\mathrm{CH}_{2} \mathrm{CH}\left(\mathrm{CH}_{3}\right)$ (Fig. 2). In 2013, the global market for polypropylene was about 55 million metric tons [12].

The properties of polypropylene depend on the molecular weight with its distribution, crystallinity, type and proportion of comonomer [13]. The density of PP is between 0.895 and $0.92 \mathrm{~g} / \mathrm{cm}^{3}$, therefore it is plastic with the lowest density. Its Young's modulus is between 3500$3900 \mathrm{MPa}$. The PP is normally tough and flexible and has good resistance to fatigue and it is reasonably economical and has a melting point that ranges from 160 to $166^{\circ} \mathrm{C}$ $[16,17]$. At room temperature, $\mathrm{PP}$ is resistant to fats and almost all organic solvents. At elevated temperature, PP can be dissolved in non-polarity solvents [18]. The polymer used in this investigation commercially available obtained from Scientific Bureau in Baghdad which is called polypropylene fibers (RHEOFIBRE). These polymer fibers are environmentally accepted and were used to adapt clay soil using different proportions. Figure 3 shows the used polymer with some of its important properties listed in Table 2.

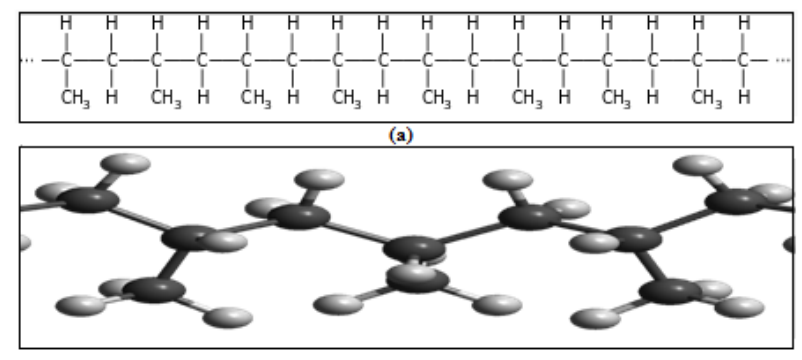

(b)

Fig. 2 (a) Structures of polypropylene with isotactic tacticity [14]. (b) Polypropylene isotactic ball-and-stick model with 3 countable monomers [15].
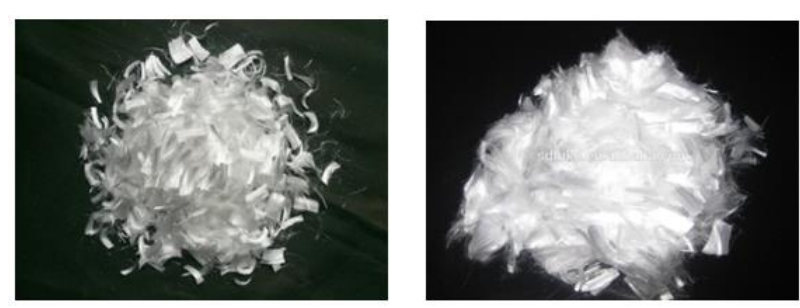

Fig. 3. Polymer used (polypropylene fibers- RHEOFIBRE).

Table 2. Physical and engineering properties of the polymer used (polypropylene fibers- RHEOFIBRE) [19].

\begin{tabular}{|c|c|}
\hline Property & Value \\
\hline Specific gravity & 0.91 \\
\hline Alkali content & Nil \\
\hline Sulphate content & Nil \\
\hline Air entrainment & $\begin{array}{c}\text { Air content will not be } \\
\text { significantly increased }\end{array}$ \\
\hline Chloride content & Nil \\
\hline Constituents & Polymerized Polypropylene \\
\hline Fiber diameter & 18 micron \\
\hline Fiber length & $12 \mathrm{~mm}$ \\
\hline Surface area & $230 \mathrm{~m}^{2} / \mathrm{kg}$ min. \\
\hline Young's modulus & $3500-3900 \mathrm{MPa}$ \\
\hline Tensile strength & $\mathrm{Min} 350 \mathrm{MPa}$ \\
\hline Melting point & $160{ }^{\circ} \mathrm{C}$ \\
\hline
\end{tabular}

\subsubsection{Water}

Tap and distilled water was used in the experiments. 


\subsubsection{Samples preparation}

To investigate the effect of polymer fiber material on the geotechnical properties of the soft soil used, soil-polymer mixtures were prepared using different percentages of polymer material.

At first, the clayey soil was dried and grinded before using it in the mixtures. Then, the required amounts of clayey soil and reinforcement polymer fibers were blended together under dry conditions. Considerable time and attention were spent to get a homogeneous distribution of the fibers in the mixtures. The contents of polymer fibers were chosen as $0,1.5,3$, and $5 \%$ by total weight of dry soil. It is worth to mention that all the testing

specimens were compacted at lowest density of 1.488 $\mathrm{gm} / \mathrm{cm}^{3}$, and the maximum water content of $23.3 \%$, corresponding to the values obtained in the Standard Proctor Compaction Tests [20]. All experimental works were carried out in the Soil Mechanics Laboratory of the Department of Building and Construction EngineeringUniversity of Technology.

\section{Experimental tests}

In this study, laboratory experiments were achieved to assess the effect of polymer addition on the physical properties, compaction, undrained shear strength and consolidation parameters of the untreated (unstabilized) and treated (stabilized) soft clayey soil samples.

Experimental work includes; specific gravity, compaction, optimum moisture content, Atterberg's limits, unconfined compressive, Vane shear, and consolidation tests.

Many geotechnical properties have been studied such as consistency limits (Atterberg's limits: liquid limit L.L, plastic limit P.L., and plasticity index P.I.), maximum dry unit weight $\left(\gamma_{\text {dry max }}\right)$, optimum moisture content $(\mathrm{OMC})$, specific gravity $\left(\mathrm{G}_{\mathrm{s}}\right)$, undrained shear strength $\left(\mathrm{c}_{\mathrm{u}}\right)$ and consolidation parameters (compression index $\mathrm{C}_{\mathrm{c}}$, and recompression index $\mathrm{C}_{\mathrm{r}}$ ) of the soft clayey soil.

As aforementioned, all the tests have been conducted after choosing the worst case, i,e., by taking the lowest density and maximum water content. Then, static compaction was applied by using the modified proctor mold to study the effect of polymer different percentages on clay by checking the unconfined compressive strength, Vane shear, and consolidation tests.

\subsection{Effect of polymer on soil properties}

For the natural and stabilized samples (after addition 1.5, 3 , and $5 \%$ polymer), the above mentioned same tests and procedures were followed.
The specific gravity of soil was determined according to ASTM D 854-02 [10]- Standard test for specific gravity of soil solids by water pycnometer. Figure 4 shows the specific gravity variation with different polymer contents.

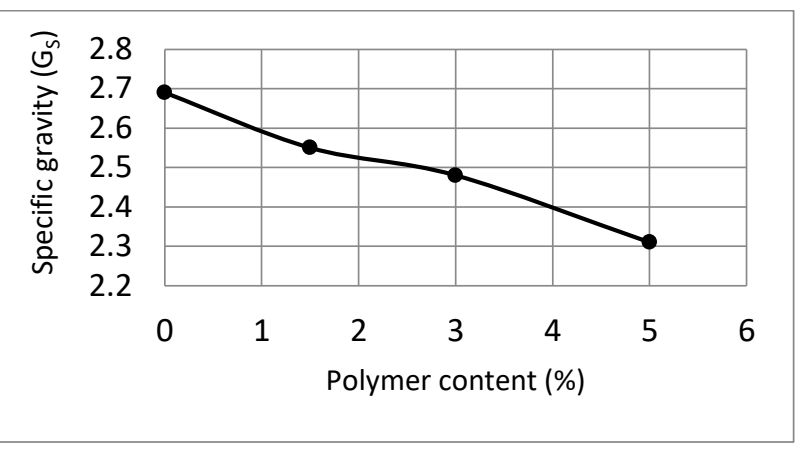

Fig. 4. Specific gravity variation with different polymer contents.

\subsubsection{Compaction}

This test was performed according to ASTM D 1557 [20] to define the relation between the dry unit weight and the moisture content of the soil. Figure 5 shows the optimum moisture content (OMC) obtained from compaction test for untreated ( $0 \%$ polymer) and treated $(1.5,3$ and $5 \%$ polymer) soils.

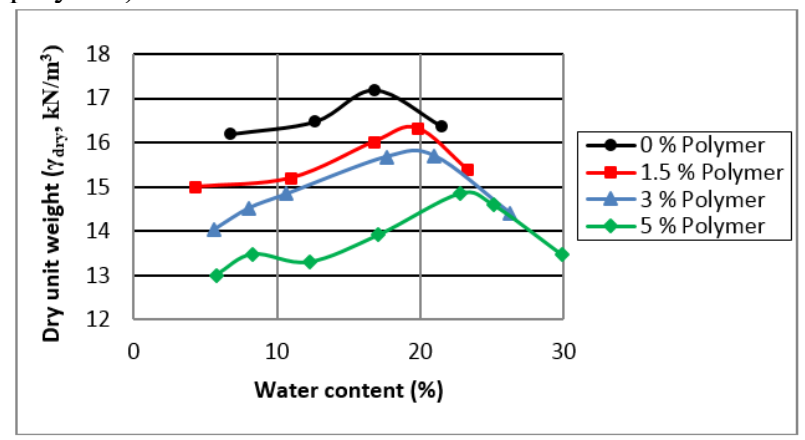

Fig. 5. Optimum moisture content (OMC) obtained from the compaction test for untreated and treated soils.

From compaction test, the maximum dry density variation and the optimum moisture content (O.M.C) with different polymer contents are presented in Table 3, and displayed in Figures 6 and 7.

\subsubsection{Specific gravity}


Table 3. Maximum dry unit weight and optimum water content.

\begin{tabular}{|c|c|c|}
\hline $\begin{array}{c}\text { Polymer } \\
(\mathbf{\%})\end{array}$ & $\begin{array}{c}\text { Max. dry unit } \\
\text { weight }\left(\boldsymbol{\gamma}_{\text {dry }}\right) \\
\left(\mathbf{k N} / \mathbf{m}^{\mathbf{3}}\right)\end{array}$ & $\begin{array}{c}\text { Optimum moisture } \\
\text { content (O.M.C) }(\%)\end{array}$ \\
\hline 0 & 17.2 & 16.25 \\
\hline 1.5 & 16.38 & 19.3 \\
\hline 3 & 15.82 & 19.8 \\
\hline 5 & 14.88 & 23.2 \\
\hline
\end{tabular}

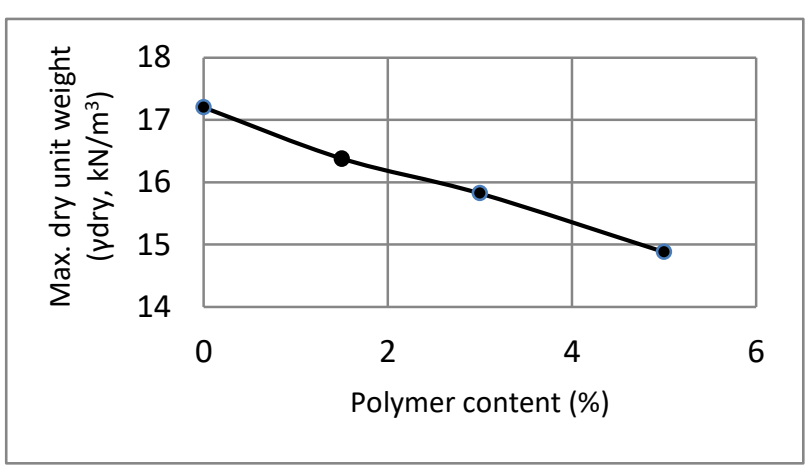

Fig. 6. Maximum dry unit weight variation with different polymer contents.

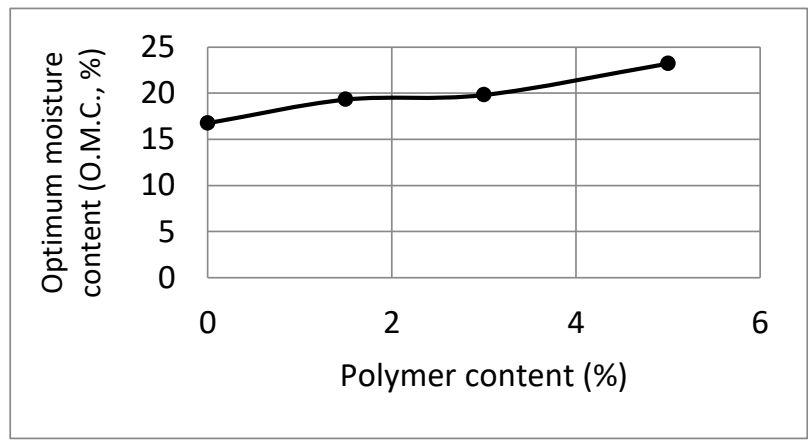

Fig. 7. Optimum moisture content variation with different polymer contents.

\subsubsection{Moisture content}

This test was performed to determine the water (moisture) content of soils. Table 3 and Figure 7 illustrate the optimum moisture content variation with different polymer contents.

\subsubsection{Atterberg's limits}

A wide variety of soil engineering properties have been correlated with consistency limits (Atterberg's limits). Liquid Limit (L.L) and plastic limit (P.L) were carried out according to the ASTM D 4318-00 [9]. Figure 8 illustrates the variations of these limits with polymer content.

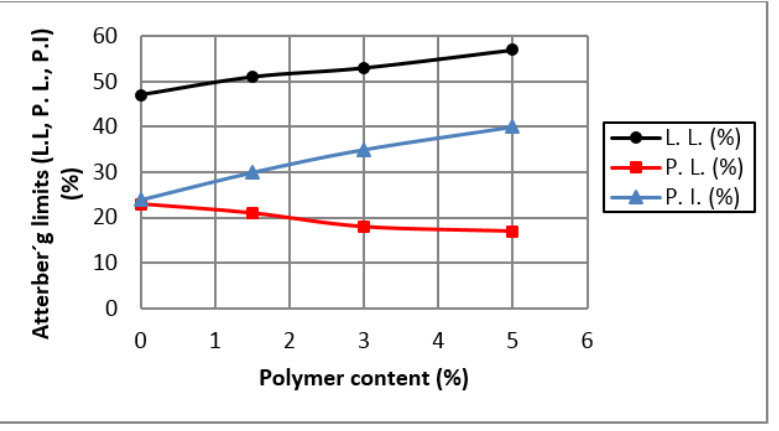

Fig. 8. Atterberg's limits variation with polymer content.

\subsubsection{Unconfined compressive strength}

Unconfined compressive test was applied to determine the unconfined compressive strength (UCS, $q_{u}$ ) following the procedure of the ASTM D 2166-00 [21] Standard Test Method for a cohesive soil. Then, the undrained shear strength (or undrained cohesion, $s_{u}$ ) of a cohesive soil was calculated which is equal to one-half the unconfined compressive strength $\left(q_{u}\right)$. The Vane shear test was also used to estimate the undrained shear strength of fully saturated clays without disturbance according to ASTM D 4767- 04ASTM D2573- 08 [22] Standard Test Method for Field Vane Shear Test in cohesive soil. Figure 9 illustrates the stress-strain relationship from the unconfined compression test for untreated and treated soils. The results of undrained shear strength values for both UCS and Vane shear tests on natural and stabilized soils with different polymer contents are presented in Figure 10.

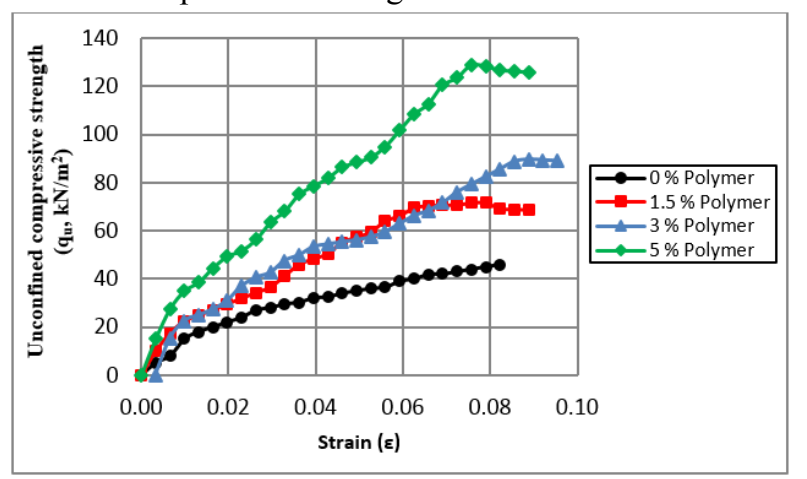

Fig. 9. Effect of polymer content on the unconfined compressive strength.

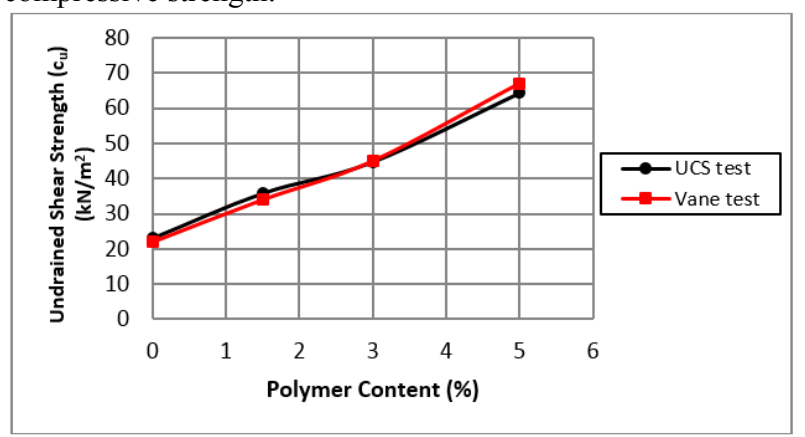

Fig. 10. Effect of polymer fibers content on undrained shear strength of soil. 


\subsubsection{Consolidation test}

This test is performed according to ASTM D 2435-02 [23] Standard Test Method for One-Dimensional Consolidation Properties of Soils. Loading pressures were $25,50,100,200,400$ and $800 \mathrm{kPa}$ and reloading pressures were $800,200,50$, and $25 \mathrm{kPa}$. From e- $\log \mathrm{p}$ relation, the compression index $\left(\mathrm{C}_{\mathrm{c}}\right)$ and recompression index or swelling index $\left(\mathrm{C}_{\mathrm{r}}\right)$ during unloading were determined at different polymer contents. Figure 11 shows the consolidation test results by relating of e- $\log p$ with polymer addition. While, Table 4 shows results of compression index and recompression index values by using different polymer content.

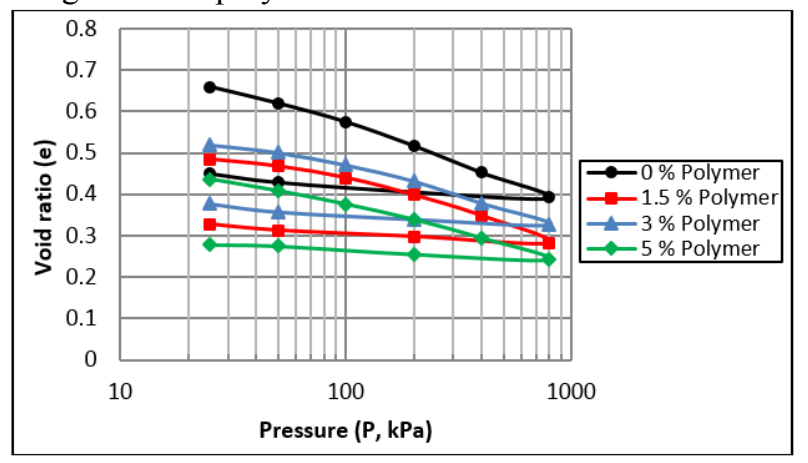

Fig. 11. Relation of e- $\log \mathrm{p}$ for untreated and treated soils with polymer addition.

Table 4. Compression index $\left(\mathrm{C}_{\mathrm{c}}\right)$ and recompression index $\left(\mathrm{C}_{\mathrm{r}}\right)$ by using different polymer content.

\begin{tabular}{|c|c|c|}
\hline $\begin{array}{c}\text { Polymer } \\
(\mathbf{\%})\end{array}$ & $\begin{array}{c}\text { Compression } \\
\text { index }\left(\mathbf{C}_{\mathbf{c}}\right)\end{array}$ & $\begin{array}{c}\text { Recompression } \\
\text { index }\left(\mathbf{C}_{\mathbf{r}}\right)\end{array}$ \\
\hline 0 & 0.191 & 0.038 \\
\hline 1.5 & 0.139 & 0.025 \\
\hline 3 & 0.129 & 0.029 \\
\hline 5 & 0.122 & 0.031 \\
\hline
\end{tabular}

\section{Testing results and discussion}

As aforementioned, it was desired in this research to evaluate the effectiveness of the clayey soils mixed with polymer fiber material (polypropylene fibersRHEOFIBRE) as a stabilizer agent. The results of physical and mechanical properties before $(0 \%$ polymer $)$ and after $(1.5,3$, and $5 \%$ polymer $)$ shall be discussed in this section.

The addition of polymer fibers affects soil's specific gravity. It is obvious from Figure 4 that with increasing polymer content, the specific gravity of treated soil sharply drops from 2.69 for untreated natural clayey soil to 2.31 after $5 \%$ polymer addition. That is due to the very low specific gravity of the polymer (0.91) compared with that of natural clay soil.

The effect of increasing polymer fibers content addition on soil unit weight is illustrated in Figure 5. It is clearly shown that here is a sharp decrease in dry unit weight and increase in optimum water content with an increase in polymer content. That is due to the light unit weight of the polymer fibers $\left(0.91 \mathrm{gm} / \mathrm{cm}^{3}\right)$. Figure 6 illustrates the influence of polymer addition on the maximum dry unit weight. From this figure, it is clear that for any particular amount of polymer, a sharp decrease in maximum dry unit weight is accompanied due to increasing polymer addition. The explanation is that due to the decline in the average value of the unit weight of the solids in the soil-polymer mixture. Knowing that the maximum dry unit weight of soil ranges from $17.2 \mathrm{kN} / \mathrm{m}^{3}$ for untreated to $14.88 \mathrm{kN} / \mathrm{m}^{3}$ at 5 $\%$ polymer addition.

The optimum moisture content (OMC) is increased with increasing the amount of polymer content (Fig. 7). The OMC values gradually increase to $3 \%$ polymer and then considerably increase to $23.2 \%$ at $5 \%$ polymer addition compared to $16.75 \%$ for untreated soil.

Concerning the effect of fiber content on Atterberg's limits shown in Figure 8, it was noticed that with increasing polymer content there was an increase in liquid limit and plasticity index from 47 and $24 \%$ for untreated to 57 and $40 \%$ at $5 \%$ polymer addition respectively. While, for plastic limit, the reverse is true, it decreases from 23 to $17 \%$ for untreated and treated $(5 \%$ polymer) respectively. As a general trend, this could be due to its higher water absorption affinity (i.e. water needed for hydration).

As regards the results of the unconfined compressive strength and Vane shear tests in case of untreated soil sample, the stress increases gradually with the increase of strain. While for the treated soil, the stress is rapidly increased with the increase of strain. The stress-strain curves of the unconfined compressive test (Fig. 9) showed increase in unconfined compressive strength $\left(\mathrm{q}_{\mathrm{u}}\right)$ from $46.14 \mathrm{kN} / \mathrm{m}^{2}$ for untreated to $128.93 \mathrm{kN} / \mathrm{m}^{2}$ for $5 \%$ polymer addition. By examining stress-strain curves, it can be stated that the addition of polymer (particularly 5\%) modify the soil behavior and deformation characteristics in term of brittleness or ductility. Moreover, this addition leads to increase in brittleness behavior of the treated soil and also to increase its stiffness (or the modulus of elasticity, E). Thus, the undrained shear strength obtained from these tests shows linear and sharp increase with polymer content for treated clayey soil particularly for $5 \%$ polymer which is more than three times that of the untreated soil (Fig. 10).

For consolidation test (Fig. 11), the results of compression index $\left(\mathrm{C}_{\mathrm{c}}\right)$ and recompression index $\left(\mathrm{C}_{\mathrm{r}}\right)$ (Table 4) show a decrease in these parameters with increasing polymer content. It has been found that the polymer stabilization markedly reduced the compression index values. The original specimens vary from a void ratio of approximately of $0.659-0.391$ over a stress range of $25-800 \mathrm{kPa}$. The values of $\mathrm{C}_{\mathrm{c}}$ and $\mathrm{C}_{\mathrm{r}}$ for the sample without stabilization were found to be 0.191 and 0.038 respectively and reduced gradually to 0.122 for the first parameter and partially reduced to 0.031 for the second one at polymer content of $5 \%$ respectively. The treated specimens have very similar compression behavior, with a void ratio varying according to the polymer contents over the same stress range. The values of compression index reduced gradually and were found to be $0.139,0.129$ and 0.122 at a polymer content of 1.5 , 3 and $5 \%$ respectively. While, the recompression index 
partially reduced, i.e., it reduces then increases again at 3 and 5\% polymer addition but still with lower values compared to the untreated soil.

The explanation is with increasing polymer content, the consolidation parameters were generally reduced as the polymer generates high tension effect between soil particles, so it is hard to compress the particles and also hard to gain the first situation. Where the $\mathrm{C}_{\mathrm{c}}$ was totally reduced while the $C_{r}$ was partially reduced but still with lower values compared to the untreated soil. Finally, similar results were obtained by Azzam (2014) [1] concerning the increase in shear strength and cohesion as well as the decrease in consolidation parameters.

\section{Conclusions}

This study was conducted to investigate the influence of polymer (polypropylene- RHEOFIBRE) addition on geotechnical properties of clayey soil. From the extensive experimental test results of this study, the following conclusions can be drawn:

1. As the polymer fiber content increases the specific gravity decreases due to low specific gravity of the polymeric material (0.91) compared with that of clay soil (2.69).

2. Compaction results indicated that there were decreasing compaction curves reflecting approximately linear decrease in maximum dry density and approximately linear increase in optimum water content as the polymer content increases.

3. For Atterberg's limits, an increase in both liquid limit and plasticity index, and a decrease in plastic limit were observed with increasing polymer content.

4. Undrained shear strength obtained from both unconfined compression and Vane shear tests show linear increase with a polymer concentration up to $5 \%$ for all the clayey soils used as the polymer plays a major role in increasing the tension between soil particles in the soil-fiber mixture.

5. The increase in polymer addition leads to an increase in the brittleness behavior of the treated soil and also to an increase in its stiffness.

6. With an increase of polymer content, the consolidation parameters (compression index $\mathrm{C}_{\mathrm{c}}$ and recompression index $\mathrm{C}_{\mathrm{r}}$ ) are generally reduced.

7. The soil stabilization with polymer fibers of polypropylene is considered as a good option as it enhances the soil strength behavior, is environmentally accepted, and is commercially available.

\section{References}

1. W.R. Azzam, Alexandria Eng J 53, 143-150 (2014)

2. H.H. Karim, Z.W. Samueel, S.F. Ahmed, Proceedings of the $2^{\text {nd }}$ International Conference of Buildings, Construction and Environmental Engineering, American University of Beirut (BCEE2), 17-18 Oct., 2015, Geotechnical Engineering Part, 117-121 (2015).
3. W.H. Perloff, Soil Mechanics: Principal and applications, (John Wiley \& Sons, 1976)

4. B.K.G. Theng, Clay and Clay Minerals 30, 1-10, (1982)

5. A. Ates, Hindawi Publishing Corporation, Int $\mathrm{J}$ Polymer Sci, Vol. 2013, Article ID 356214, 8 P. (2013)

6. K. E. Clare, A. E. Cruchly, Geotechnique 7, 97-110 (1957)

7. A. Amadi, Leonardo El J Pract Technol 17, 69-78 (2010)

8. S.F Ahmed, M.Sc. Thesis, University of Technology (2015)

9. ASTM D 4318-00, Standard test methods for liquid limit, plastic limit, and plasticity index of soils, (ASTM International, West Conshohocken, PA, United States, 2000)

10. ASTM D 854-02, Standard test methods for specific gravity of soil solids by water Pycnometer, (ASTM International, West Conshohocken, PA, United States, 2002)

11. ASTM D 422-63 (Reapproved 2002), Standard test method for particle size analysis of soils, (ASTM International, West Conshohocken, PA, United States, 2002)

12. Ceresana: Market Study: Polypropylene, (3rd edition), 580 P., available on http://www.ceresana.com

13. D. Tripathi, Practical guide to polypropylene, Shrewsbury: RAPRA Technology, (2001)

14. Mediawiki/RicHard-59, File: Polypropylene tacticity.svg, (2012)

15. PakpongICCH444, File:Polypropylene isotactic mini trp.png. (2015)

16. C. Maier, T. Calafut, Polypropylene: the definitive user's guide and databook, (William Andrew Inc, USA), 430 P. (1998)

17. W. Kaiser, Kunststoffchemie für Ingenieure von der Synthese bis zur Anwendung, (3 ${ }^{\mathrm{rd}}$ ed., München: Hanser, 2011)

18. S. Koltzenburg, M. Maskos, O. Nuyken, Polymere: Synthese, Eigenschaften und Anwendungen, (Springer, 2014)

19. BASF, the Chemical Company, "RHEOFIBRE", Construction Chemicals UAE LLC, (2004), available on http://www.mediawiki.org/wiki/User:RicHard-59

20. ASTM D 1557, Standard test methods for laboratory compaction characteristics of soil using modified effort $\left(56,000 \mathrm{ft}\right.$-lbf/ft $\left.{ }^{3}\left(2,700 \mathrm{kN}-\mathrm{m} / \mathrm{m}^{3}\right)\right)$, (ASTM International, West Conshohocken, PA, United States, 2000)

21. ASTM D 2166-00, Standard test method for unconfined compressive strength of cohesive soil, (ASTM International, West Conshohocken, PA, United States, 2000)

22. ASTM D 4767 - 04ASTM D2573 - 08, Standard test method for field Vane shear test in cohesive soil, (ASTM International, West Conshohocken, PA, United States, 2008)

23. ASTM D 2435-02 (ASTM International, West Conshohocken, PA, United States, 2002) 